\title{
The Relationship between Emotional Intelligence and Religious Attitudes with Mental Health of High School Students in Neka City
}

\author{
Omoul Banin Mousavi Chamani
}

\author{
Department of Psychology, Sari Branch, Islamic Azad University, Sari, Iran
}

Doi:10.5901/mjss.2016.v7n3s2p118

\begin{abstract}
The aim of this study is to determine the relationship between emotional intelligence and religious attitude and mental health of high school students of Neka city. The study population includes all high school students in Neka city that number of them according to the given statistics is equal 3844 people. Kerjesy and Morgan table has been used to determine the sample size. According to Morgan table sample size is equal 348 people. The research's sample has been selected between students by stratified random sample based on gender. Data collection methods had been included: Library and field. The collecting data tool in this research was used shot and et.al Emotional intelligence questionnaire, the Goldenberg public Health Questionnaire and religious attitudes. Also Questionnaire's reliability has been calculated by using Cranach's alpha to emotional intelligence Questionnaire 0.92, mental health Questionnaire 0.83 for religious attitude questionnaire 0.74. In this study, the methods of descriptive statistics (frequency distribution, mean, standard deviation, variance and percent) and inferential statistics (Pearson correlation and multiple regressions) and two independent $t$ tests are used to summarize and analyze research's data. SPSS statistical software has been used in this study. The results showed there is a direct relationship between emotional intelligence and student's mental health. Also there is a direct relationship between religious attitudes and students mental health. Both emotional intelligence and religious attitudes variables have contribute to prediction of student's mental health.
\end{abstract}

Keywords: Emotional Intelligence, religious attitude, mental health

\section{Introduction}

Mental health refers to inner feeling of well-being and ensure of own efficiency, rely on own, competition capacity, intergenerational dependence and self-actualization of intellectual and emotional potential capability and so on.

Of course, by considering between cultural differences, comprehensive definition of mental health is impossible. However, there is consensus on the fact that mental health is more than the absence of mental disorders and what is certain is that maintaining mental health as well as physical health is important (Abbas, 2012, p. 42) one of the items of various community health assessing is mental health of that community. Undoubtedly, mental health plays an important role in dynamics and efficiency Guarantee of every society. Since the students are the talented people, society elected and builders of country's tomorrow, therefore their mental health have scientific importance in learning and increasing science knowledge (Sami, 2014). The basic necessities of student life is student's mental health ,attention to that has direct effect on growth and development of Society and paying to that is basic condition in optimum productivity of efficient and educated staff. Student period is considered a specific period for reasons such as being away from family, participation in social responsibility, temporal association of this period with adolescence and youth conditions, educational and academic pressures.

Enter to universities associates with changes in social and human communications. In addition to these changes should be pointed to new roles and expectations that are formed when students enter to university. Being in this situation is associated often with stress and Worry and effects on the persons' performance and efficiency (Austin, 2009).

On the other hand having psychological problems lead to problems for doing homework, lack of motivation, anxiety and fears and cause that students spend a significant portion of its intellectual force to these problems. As a result, surly it will not have sufficient interest for operating in curriculum and teaching affairs. Changes in relationships with family and friends, eating and sleeping habits and as well as loneliness will be have the opposite effect on some students (Carson, 2009).

By looking to done studies is seen that factors such as emotional intelligence and religious attitudes associate with mental health. It is said that emotional intelligence is something inside each of us that is somewhat intangible. Emotional intelligence determines how manage ours behavior, how to deal with social problems and how to take decisions that will lead to positive results (Bradbury and Grevers, 2012). 
Emotional intelligence connects with recognizing a person of own and others, relation with others and adjusting with environment that is necessary to be successful in social demands meeting and is counted a tactical capabilities in individual performance; While cognitive intelligence has strategic and long-term capabilities. Emotional intelligence makes possible success predict, because it shows how person applies owns knowledge in different situations immediately. In other words, emotional intelligence refers to peoples' differences in perception, process, adjust and using emotional information (Mayer, J. D., Salovey, P, 2008.)

But according Bar-on definition (2006) Emotional intelligence is a set of knowledge's and Emotional and social abilities that affected our overall capabilities in response to the environmental needs effectively. This set includes the following: 1. Be aware of own ability, understanding own and power of emotions expression, (2) ability to be aware of others, understanding others and its expressing power, 3. the ability to deal with intense emotions and impulses control in own, 4. ability to adapt with changes and solve problems with social and personal nature. Several studies based on the relationship between emotional intelligence with physical and mental health have been conducted. The results show that emotional intelligence both directly and indirectly associated with mental health. Each components of emotional intelligence affect in a way to mental health quality. Other factors associated with mental health, is people's religious attitude.

About The impact and important of religious beliefs on mental health have been done many discussions from past to present and in recent years psychologists have emphasized the role of religion in mental health and mental illness treatment. They believe in faith to God and religious attitude is extraordinary power that gives spiritual power to human kind And help to mankind in life's hardships and far away the anxiety that many people in ours period are at risk. (Sharifi, 2013)

World Health Organization in its latest statement that has been published in the past decade and especially in the introduction of projects during that has been intended health programs for developing countries has examined the health of the four basic aspects of the physical, psychological, social and spiritual dimension. Emphasis on fourth dimension means spirituality represents awareness of officials and mental health experts and emphasizes on importance of religion and spirituality in the life of society.

Among those who have emphasized to the importance of religious studies, can be minded of the American Psychiatric father Benjamin Rush; he said religion is important for soul Health Education as the air to breathe (Maltby, 2011).

Considering the presented material, the researchers' wants to answer the main question whether there is relation between emotional intelligence and religious attitudes with mental health of high school students in the Neka city?

In this regard Bakhshayesh (2016) in a study as relationship of trust, self-esteem and academic concludes that there is a relationship between trust in God and self-esteem. Also Sasani Moghadam \& Bahr Al Olom (2015) in a study as " The relationship between emotional intelligence and students' mental skills of female athlete of Shahrood industrial University that were analyzed descriptive statistics and correlations between variables, came to this conclusion that there is a significant and positive correlation between emotional intelligence and confidence, relaxation, refreshment and again focus.

Homaee and et.al (2015), in a study as relationship between emotional intelligence, and religious attitude of demographic variables with students' academic performance of Ahvaz's Islamic Azad University; were selected 239 people of mentioned society by Stratified sampling method. Come to this conclusions that multiple regression by step to step method is the best predictor of students' academic performance that in order was Diploma average, gender and emotional intelligence and other variables such as achievement motivation, cognitive intelligence, marital status, employment status, age and be native or not and amount of income are evaluated and did not showed significant correlation with academic performance.

Shahni Yeelagh et.al (2014) in a study as impact of emotional training on social anxiety, social adjustment and emotional intelligence of male and female students achieved these results that multivariate variance analyzing indicates significant differences between social anxiety, social adjustment and groups' emotional intelligence.

In addition, between two genders in terms of emotional intelligence training on dependence variables was not seen significant difference. Augusto Landa et al. (2013) in a study as emotional intelligence self-perception and life satisfaction of university's professors came to this conclusion that there is strong relationship between life satisfaction and emotional intelligence measuring subscales and sub-scales of alexi thymia Measure and job satisfaction. Further analyzes showed that life satisfaction is the most important predictor of positive and negative emotions and Emotional clarity.

Also Karademas (2012) founds in a research that optimism component in emotional intelligence moderates selfefficacy relationship and perceived social support with various aspects of Psychological well- being such as life satisfaction and causes to develop using of problem-focused coping strategies and emotions regulation. The research's 
sample has been selected by using stratified random sample method according gender among students. Data collection method had been included: Library and field. Emotional intelligence questionnaires of shot and colleagues, the Goldenberg's General Health Questionnaire and religious attitude was used to collecting data tool in this research.

\section{Analyzing Method}

The correlation is research's method in this research and to evaluate the relationship between emotional intelligence and religious attitude with Neka's high school students mental health by using Kerjesi and Morgan table has been selected 348 person as stratified random sampling method according gender among all the high school students that Their populations according statistic is equal 3844 people.

Data collection method had been included: library and field .collecting data tool in this research was used emotional intelligence questionnaires of shot and colleagues, the Goldenberg's General Health Questionnaire and religious attitude. Also Questionnaire reliability by using Cronbach's alpha has been calculated 0.92 for emotional intelligence, 0.83 for mental health questionnaire and 0.74 for religious attitude questionnaire.

In this study, is used descriptive statistics methods (frequency distribution, mean, standard deviation, variance and percent) and inferential statistics methods (Pearson correlation and multiple regression) and two independent $t$ test for summarizing and analyzing research's data.

The SPSS statistical software was used in this study.

\section{Findings}

Demographic Findings showed that women Have allocated 68\% of the subjects (most frequent) and men 32\% (lowest frequency).

According to the Pearson table (number 1) the amount of Sig (significance level) is significant in 0.05 error level ( $\operatorname{sig}=0.000<a=0.05$ ), Thus, this result was achieved with $95 \%$ confidence that There is a relationship between two variables and in fact there is a direct relationship between emotional intelligence and students' mental health .

Table 1: Statistical analysis of the first hypothesis

\begin{tabular}{lccc}
\hline Variables & Pearson coefficient Error rate $(\alpha)$ Sig (significance level) \\
\hline Emotional Intelligence and mental health & 767.0 & 05.0 & 000.0 \\
\hline
\end{tabular}

According to the Pearson table ( number 2) the amount of Sig (significance level) is significant in 0.05 error level (sig $=0.000<a=0.05$ ), Thus, this result was achieved with $95 \%$ confidence that There is a relationship between two variables and in fact there is a direct relationship between Religious Attitude and students' mental health.

Table 2: Statistical analysis of the second hypothesis

\begin{tabular}{lccc}
\hline Variables & Pearson coefficient & Error rate ( $\alpha)$ & Sig (significance level) \\
\hline Religious Attitude and mental health & 641.0 & 05.0 & 000.0 \\
\hline
\end{tabular}

Results of regression analysis (Table 3) show that the overall correlation between research's variables is equal 0.779 which represents the relatively modest correlation between the research's variables. Also according to the determination coefficient, this result is concluded that variables of emotional intelligence and religious attitude allocate $0.639 \%$ of mental health changes to own and the others are related to other factors that have not been examined in this research.

Table 3: Regression model's Summary

\begin{tabular}{cc}
\hline $\mathbf{R}$ (correlation between variables) & $\mathbf{R}^{2}$ ) coefficient of determination( \\
\hline 799.0 & 639.0 \\
\hline
\end{tabular}

As can be seen in Table 4, both emotional intelligence and religious attitude variables remain in the regression model and in fact have a share in predicting students' mental health that among them emotional intelligence variable has larger share in predicting students' mental health and religious attitudes variable places in next rate. 
Table 4: Regression coefficients

\begin{tabular}{ccccl}
\hline & & Standardized coefficients & \multicolumn{2}{c}{ Non-standardized coefficients } \\
\cline { 3 - 5 } Sig & $\mathbf{t}$ & Beta & standard error & \\
\hline 014.0 & 48.2 & & 23.4 & Fixed amount \\
\hline 000.0 & 23.17 & 732.0 & 01.1 & Emotional Intelligence \\
\hline 000.0 & 36.5 & 228.0 & 84.0 & Religious Attitude \\
\hline
\end{tabular}

\section{Debate and Interpretation}

The first hypothesis results show a direct relationship between emotional intelligence and mental health of students. This result is consistent with the results of Bakhshayesh (2015), Sasani (2014), Gharibi (2013), Homaee (2014), Augusto Linda and et al. (2013) and Karademas (2013).

The results showed that how much subjects' emotional intelligence be in better state they have high mental health.

In fact, people who have high emotional intelligence when speak with others, be aware about their personal problems and when are encountered with a barrier in their way, reminds the times that had been encountered with same barriers and finally prevailed to them. Also they have expectation and hope that they do well the works that try to do them. These persons have high mental health. The results of the second hypothesis show that there is a direct relationship between religious attitudes and students mental health that these results are aligned with results of Bakhshayesh (2016), Sasani Moghadam (2015), Gharibi (2014), Homaee and et al. (2015), Augusto Linda and et.al. (2013) and Karademas (2013)research. The results showed that how much religious attitudes of subjects be in a better state also have high mental health. In fact, people who have high religious beliefs, believe that happiness key is Following the religious rules and human happiness is not provided only through the science advancement and religion is not science advancement barrier. Also believe spiritual Happiness does not depend on the material happiness and when a person spiritually is succeed, his happiness is complete. Also they have high mental health.

The results of the third hypothesis show that both emotional intelligence and religious attitudes variables have a share to prediction of students' mental health, emotional intelligence variable has larger share in predicting mental health of students and religious attitude places in next rate that these results Are aligned with results of Bakhshayesh (2016), Sasani Moghadam (2015), Gharibi (2014), Homaee and et al. (2015), Augusto Linda and et.al. (2013) and Karademas (2013(research. In fact, people who are aware of the emotions that they experience and looking for good things happening and like to share feelings and emotions with others. They also believe that religious beliefs and wavering faith is the source of moral corruption and religious tells the facts of life and is the person's best guide in life that as a result these people have high mental health.

\section{References}

Abbas, omid. (2011), mental health, a new understanding, new hope, Tehran, great Ibn Sina Cultural Institute.

Sami, Curosh. (2013), the mental health status of students of Medical Sciences, Tehran University of Medical Sciences, Issue 34,35

Bradbary, trois. And Graves, Jane. (2011). Emotional intelligence (skills and tests), publishing Savalan, p. 153.

Sharifi, T. (2012), attitude and Demme Public Health and Patience in Students of Ahvaz Islamic Azad University, Journal of Thought and Rftarf eleventh year, No. 1, p. 89

Sassanid moghaddam, Shiva. And Bahr al-Hassan. (2014). The relationship between emotional intelligence and mental skills of female student-athlete, Shahrood University.

Shahniye yeylaghi, Manijeh, maktabi, GH; Shokrkon, Hossein, Haghighi, Jamal. And Kianpour Ghahfarokhi, Fatima. (2013). The effect of training on social anxiety, emotional, social adjustment and emotional intelligence male and female students, achievments journal Psychological Science (and psychologically), Shahid Chamran University of Ahvaz, Volume IV, Vol. 16, Issue 1, Pages: 3-26.

Homai, R, Heidari, AR; Bakhtiyarpour, Said. And Bornna, MR. (2014). Relationship between achievement motivation and cognitive intelligence, emotional intelligence, educational background and demographic variables and academic performance, new findings in psychology, pp: 49-63.

Augusto Landa, J.M., Lopez-Zafra, E., Martinez de Antonana, R., and Pulido, M. (2013). Perceived emotional intelligence and life satisfaction among university teachers, Psicothema, Vol. 18, supl., Pp. 152-157.

Austin EJ, Saklofske DH, Egan V. (2009). Personality, well-being and health correlates of trait emotional intelligence, Personality and Individual differences, 38: 547-558.

Carson, K., Carson, P.F.K., Birken meier, B. (2009). Measuring Emotional in telliyence: deve Lop ment and validiation of an in Strument. The Journal of Behavioral and Applied Management Review, 12, 237-268

Mayer, J. D., Salovey, P., \& Caruso, D. R. (2008). A further consideration of issues of emotional intelligence. Psychological Inquiry, 15, 
249-255.

Bar-on, R (2006). The bar-on model of emotional intelligence skills development training, program and student achievement and retention, Unpublished raw data, texas A \& M university-kingsville.

Maltby, John., \& Day, Liza (2011). Depressive symptoms and religious orientation: Examining the relationship between religiosity and depression within the context of other correlates of depression. Personality and Individual Differences, 28, p.383-393. 